\title{
LA RHETÓRICA EN LENGUA CASTELLANA (1541) DE MIGUEL DE SALINAS Y EL OPUS DE CONSCRIBENDIS EPISTOLIS (1522) DE ERASMO. LA APLICACIÓN DE LA RETÓRICA A LAS CIRCUNSTANCIAS COMUNICATIVAS*
}

\author{
$\mathrm{M}^{\mathrm{a}}$ Amelia Fernández Rodríguez \\ (UAM-IULCE) \\ amelia.fernandez@,uam.es
}

\section{RESUMEN}

En este trabajo se aborda la influencia del Opus de conscribendis epistolis (1522) de Erasmo sobre la Rhetórica en lengua castellana de Miguel de Salinas (1541) desde la perspectiva del intento realizado por Salinas al elaborar una retórica en su propia lengua y aplicarla a las situaciones comunicativas coetáneas. El ajuste interno de la teoría realizado por Salinas hallará, en la formulación teórica de las tres omnium generum fontes establecidas por Erasmo para el arte epistolar, el camino adecuado para una integración desde los genera causarum retóricos. El trabajo se completa con la aportación de nuevos argumentos en torno a la autoría de la Rhetórica.

PALABRAS CLAVE: Retórica; Artes epistolares; Retórica de la comunicación; Retórica cultural.

\section{MIGUEL DE SALINAS' RHETÓRICA EN LENGUA CASTELLANA (1541) AND ERASMUS' OPUS DE CONSCRIBENDIS EPISTOLIS (1522). THE APPLICATION OF RHETORIC TO COMMUNICATIVE CIRCUMSTANCES}

\begin{abstract}
This work addresses the influence of Erasmus' Opus de conscribendis epistolis (1522) on Miguel de Salinas' Rhetórica en lengua castellana (1541) from the perspective of the attempt made by Salinas to elaborate a rhetoric in his own language and apply it to the contemporary communicative situations. The internal adjustment of the theory carried out by Salinas will find, in the theoretical formulation of the tres omnium generum fontes established by Erasmus for the epistolary art, the adequate way for an integration
\end{abstract}

\footnotetext{
* Este trabajo es resultado de investigación realizada en el proyecto de $\mathrm{I}+\mathrm{D}+\mathrm{i}$ de referencia PGC2018-093852-B-I00 del Ministerio de Ciencia, Innovación y Universidades.
} 
from the rhetorical genera causarum. The work is completed with the contribution of new arguments around the authorship of the Rhetorica.

KEY WORDS: Rhetoric; Epistolary art; Rhetoric of Communication; Cultural Rhetoric.

Pocos títulos hay tan descriptivos como el de Rhetórica en lengua castellana, con el aviso de que, literalmente, «se pone muy en breve lo necesario para saber bien hablar y escribir y conocer quien habla y escribe bien», acompañado de tres apéndices destinados además a este fin. ${ }^{1}$ Es en esencia lo que ofrece esta obra publicada bajo la autoría «de un fraile de la orden de sant Hierónymo» en 1541 por Joan de Brocar en Alcalá de Henares quien antecede el libro con una Epistola dirigida «Al muy alto y muy poderoso Príncipe y Señor nuestro Don Phelippe de Austria» encareciendo lo que se leerá en las páginas siguientes. El principal interés de la Rhetórica en lengua castellana, en palabras de Brocar, es el que sigue:

Muchas rhetóricas ay escritas en lengua griega, sereníssimo Príncipe, y hartas más en latín; todas ellas no salen de sus términos ni aprovechan más cada qual de a su propósito. Fue muy bien pensado que para la castellana, no menos abundante que las otras en las maneras de hablar, oviesse arte para saberse aprovechar dellas. ${ }^{2}$

Y, ciertamente, las retóricas a las que se refiere Brocar no salen de sus términos, ni aprovechan más que a su propósito, sobre todo teniendo en cuenta que la Retórica así considerada no salía de los justos límites para la que se aplicaba, los de su propio tiempo y su propia cultura. A lo que sumar un elemento más y es que la "falta de latinidad" dificulta la comprensión de las reglas del arte, siendo esta una causa más para el proyecto que entrega el autor de aplicación de la Retórica, con todas sus consecuencias, a la propia lengua y a la propia comunicación y con el complemento añadido además de la traducción y consiguiente creación de una terminología técnica en lengua castellana. ${ }^{3}$

\footnotetext{
${ }^{1}$ Citaremos por la edición de Encarnación Sánchez García, Miguel de Salinas, Rhetórica en lengua castellana (Nápoles: L’Orientale Editrice, 1999). El manual se halla complementado por tres apéndices con los que forma una unidad: "Síguese una forma para poner por exercicio las reglas de la rhetórica passada" (150-158), "Tratado de las maneras de dilatar la materia con palabras y sentencias y otras cosas quando fuere necessario. tiene dos partes, una de la abundancia de las palabras, otra de la abundancia de las cosas" (159-187) y "Forma que se deve tener en sacar los exemplos y sentencias de los autores que se leen, de manera que se apliquen a todos los propósitos que pueden hazer y se pongan por orden que de suyo se offrezcan quando fuere menester". (188-209).

2 Brocar, Joan de, "Epístola" en Salinas, Miguel de, Rhetórica en lengua castellana, ed. Encarnación Sánchez García (Nápoles: L’Orientale Editrice, 1999), 4-6, 5.

${ }^{3}$ Encarnación Sánchez García, “'Alta sciencia y provechosa': la Rhetórica en lengua castellana (Alcalá, 1541) de Miguel de Salinas", en Actas del XII Congreso de la Asociación Internacional de Hispanistas. Estudios áureos II, ed. Jules Whicker (Birmingham: University of Birmingham. Department of Hispanic Studies:
} 
La crítica ha trabajado especialmente en la novedad de la publicación de esta Rhetórica, así como de los aspectos retóricos y literarios presentes en la obra. Lo que planteamos es un abordaje que tenga en cuenta, ante todo, la movilización de la teoría retórica a efectos comunicativos, en el ejercicio constante de volcar la disciplina, no sólo al castellano sino también a las situaciones y circunstancias posibles en el que el conocimiento de la Retórica es preciso, no en vano y siguiendo además la presentación de Brocar:

Viendo esta necessidad un reverendo padre hierónymo recopiló de Trapezuncio, Hermógenes y otros rhétores griegos, de Tullio, Quintiliano y de otros modernos autores latinos, este volumen y arte de rhetórica y lo aplicó a la lengua castellana para que en ella sepamos bie $n$ hablar y bien escrevir, y conozcamos quie $n$ habla y escrive bien. ${ }^{4}$

Como acertadamente señala Encarnación Sánchez García desde la impecable edición de la obra, por la que citamos, el análisis de las fuentes utilizadas proyectadas sobre el texto, realmente cumplió con el procedimiento que adelantaba Brocar, en la doble función de "recopilar" y de "aplicar" desde una intención eminentemente funcional. ${ }^{5}$ Hemos de añadir que la novedad no sólo de aplicar la Retórica a la propia lengua, sino también la de aplicarla a las circunstancias coetáneas parece prestar la confianza posible, como veremos, para discurrir libremente por la disciplina retórica, asimilando sus principios al fin que se persigue.

Con respecto a las posibles fuentes, la atención se ha dirigido especialmente a la Artis Rhetoricae compendiosa coaptatio ex Aristotele Cicerone et Quintiliano de Nebrija, publicada en 1515 en Alcalá de Henares, a instancias del Cardenal Cisneros y en la imprenta del padre de Joan de Brocar, Arnao Guillén de Brocar. ${ }^{6} \mathrm{Y}$, sin embargo, si bien, tomado como referencia primera el esfuerzo del autor por colmar su intento, permite un interesante alejamiento tal y como se advierte en el «Prólogo del autor del libro a los lectores»:

1998), III, 221-228, 226. En definitiva, lo que está avalando Brocar puede explicarse desde los parámetros genéricos de la Retórica cultural: Tomás Albaladejo, "Cultural Rhetoric. Foundations and perspectives”, Res Rhetorica, 1 (2016): 17-29. DOI: https://doi.org/10.17380/rr2016.1.2

4 Joan de Brocar, "Epístola", 6. Para la selección de los autores y el orden establecido, véase Encarnación Sánchez García, "Introducción” a su ed. Salinas, Miguel de, Rhetórica en lengua castellana, (Nápoles: L’Orientale Editrice, 1999), v-xliii, xxxiv-xxxvii.

5 "En efecto la pareja verbal recopiló/aplicó desentraña el método bipartito del trabajo de Salinas y el haberlo detectado como clave del libro constituye el más grande elogio que Brocar podía dedicar al texto que estaba presentando, puesto que a la nobleza de las raíces se añade la novedad de una funcionalización de cuya trascendencia para el castellano el editor humanista es plenamente consciente", Encarnación Sánchez García, "Nebrija y Erasmo en la Rhetórica en lengua castellana de Miguel de Salinas", Edad de Oro, XIX (2000): 287-298, 289.

${ }^{6}$ Para una valoración histórica de la publicación de la obra de Nebrija y el vínculo con la imprenta de los Brocar, véase Sánchez García, "Nebrija y Erasmo”, 289-290, además de las páginas dedicadas en la introducción de su edición a la labor de Brocar y el subrayado de la "apertura extraordinaria" que suponía avalar y editar el texto: Encarnación Sánchez García, “Introducción”, xix-xxiii. 
Y pues la rhetórica es arte de bien hablar y todos tienen dello necessidad y, según veemos, assí en sermones como en juizios, cartas mensajeras y hablas familiares, todos hablen en su común lengua y no en latín, sería bien que uviesse arte de rhetórica en la lengua vulgar porque, a lo menos en Castilla, podríanse aprovechar della los que no saben latín para en castellano, y los que saben latín para en latín y en castellano. ${ }^{7}$

Es de tal calibre el empeño del autor que tras el prólogo a los lectores, incluye un «Aviso necesario en el que se da cuenta de las instrucciones para hacer uso del manual», ${ }^{8}$ al que sigue un "Aviso ante todo necesario» ${ }^{9}$ con dos indicaciones muy claras que revelan intensamente su propósito y comprensión profunda de las claves comunicativas de la Retórica clásica. En primer lugar indica, siguiendo principalmente a Quintiliano, ${ }^{10}$ que el dominio de la técnica, por parte del orador, no ha de revelarse en ningún momento para evitar que el receptor pueda considerarlo un engaño. ${ }^{11} \mathrm{En}$ segundo lugar, advierte que es sólo por la práctica, y explorando las propias facultades, a través de la que se ejercita la Retórica, más allá de la lectura y consulta de los manuales. ${ }^{12}$

Teniendo en cuenta los dos avisos previos, se lee a renglón seguido, «Pues, presupuesto lo dicho, comencemos el arte», y como en un círculo concluirá el manual, desde el magisterio de Quintiliano, ${ }^{13}$ quien precisamente en el Libro XI tratará sobre todo aquello que el arte no puede regular como son las circunstancias. En este caso el cierre coincide con las consideraciones sobre la puesta en escena del discurso que, por otra parte, también se seguirá en el apartado correspondiente a esta pars artis pronuntiatio - en la Rhetórica en lengua castellana:

Assí que el que ha de hablar bien deve no sólo saber el arte y exercitarle, pero conoscerse a sí mismo, y para todo es menester la discreción. Y con esto concluyo las partes de la Rhetórica. ${ }^{14}$

\footnotetext{
${ }^{7}$ Salinas, "Prólogo del autor a sus lectores", Rhetórica, 15.

${ }^{8}$ Salinas, Rhetórica, 18.

${ }^{9}$ Salinas, Rhetórica, 18-19.

${ }^{10}$ Como señala Sánchez García en su edición: “Advertencia sobre la que insiste Quintiliano: “nam si qua in his ars est dicentium, ea prima est, ne ars esse videatur" (Institutio I, XI, 3)", 18, n. 25.

11 "Antes que comience el arte que quiero poner, la primera y principal regla de la rhetórica y de que se tenga muy gra $n$ cuidado, es que, sabido muy bie $n$ el arte, se sepa dissimular, usando de tal manera de las reglas que no se pueda, oyéndole, sentir que se acuerda aun dellas. Porque si el que oye huele que se precia aprovechar de arte el que habla, o piensa que quiere engañar y guárdase, o pone la atención sólo en notar el artificio y, finalmente, es cosa odiosa sentirse que uno tenga cuidado y affectión de bien hablar, y todo el fruto se pierde y de honra no se gana nada." Salinas, Rhetórica, 18-19.

12 "Y aunque en todo tiempo es bueno, mucho más a los principios en los cuales, poniéndose la diligencia necessaria, sábese el arte, qualquiera que sea y perfectamente, de una vez. Y no ay necessidad de andar adelante siempre estudiándola, envejescidos en preceptos y en facultades que sólo sirven averse estudiado y dañan siempre estudiarse; de las quales una es la rhetórica, que quiere al principio cuidado y trabajo, y una vez bien sabida adelante se descuiden della." Salinas, Rhetórica, 19.

${ }^{13}$ Salinas, Rhetórica, 19; Quare norit se quisque, nec tantum ex communibus praeceptis sed etiam ex natura sua capiat consilium formandae actionis, Quintiliano, Institutio, 11, 3, 180.

${ }^{14}$ Salinas, Rhetórica, 44.
} 
Desde esta perspectiva, creemos que es preciso volver a la valoración sumaria que en su momento hizo Eugenio Asensio, señalando dos claves primordiales, desde nuestro punto de vista, para entenderla. Por un lado, el hecho de que no es una retórica pensada sólo para el que habla, lo es también para quién escribe, y además es fundamental, desde este punto de vista, la influencia de Erasmo y en general la consideración de las características propias del arte epistolar:

Fray Miguel de Salinas, el jerónimo aragonés, publicó anónima la Rhetórica en lengua castellana (Alcalá, 1541), que pretende con razón ser la primera en nuestra lengua. En ella, no contentándose con copiar a Erasmo y extractar abundantes trozos, aplicó las pautas del erasmismo a la composición de discursos, cartas mensajeras y otros géneros. Al principio se limita a ser una compilación de varios tratadistas con reiteradas infusiones de los textos pedagógicos del de Rotterdam. ${ }^{15}$

La presencia del Ars conscribendis epistolis de Erasmo es contundente, con una más que interesante contribución, desde nuestro punto de vista, como es la de que el autor de la Rhetórica no distingue entre el discurso oral y el escrito y se vale del ars conscribendis epistolis para diseñar pautas concretas que describen situaciones comunicativas determinadas. El afán pedagógico, la reducción de la lengua al arte, compromete en este punto al propio sistema retórico del que parte, centrado en la oratio, al alterar además significativamente el orden establecido.

Lo que ha sido completamente refrendado es la cercanía con el De copia, ${ }^{16}$ similar, en nuestra opinión, al del De conscribendis epistolis a propósito de la divisio y desde los géneros epistolares propuestos por Erasmo, con la diferencia de que el autor no cita a Erasmo de forma explícita, salvo cuando elige un ejemplo extraído del $D e$ conscribendis epistolis en el primero de los apéndices que complementan el manual, como veremos.

Por otra parte, en el «Prólogo del autor del libro a los lectores» se da cuenta de la dificultad para tomar la decisión de publicar la obra:

A mí me pidió, y con mucha instancia, cierta persona que me lo podía mandar que le hiziesse en lengua castellana un arte de Rhetórica para que con ella, no sabiendo latín, pudiesse entender algo de lo que los rhetóricos latinos y griegos ponen cerca de la sciencia del bien hablar y escrevir y aprovecharse dello. ${ }^{17}$

Peter Russell formuló la hipótesis de que esa persona que podía mandar no fuera otro que el propio príncipe - directa o indirectamente -, a quien Brocar dirige su epístola, dadas las dificultades ciertas que tenía en el conocimiento del latín. Desde

15 Eugenio Asensio, "Los estudios sobre Erasmo de Marcel Bataillon”, Revista de Occidente, VI, 63 (1968): 302-319, 317.

${ }^{16}$ Como señala E. Sánchez García: "En cuanto a Erasmo la utilización del De Copia está documentada en mi edición a partir del capítulo IX dedicado a «la narración o manera de dar cuenta de la qualidad y particularidades de la persona» y continúa en el capítulo siguiente, dedicado a la narración o pintura del lugar", "Nebrija y Erasmo", 296.

${ }^{17}$ Salinas, Rhetórica, 14. 
luego, de ser así y no tratarse de "un topos de la humildad" que Russell tampoco descarta, ${ }^{18}$ la obra estaría inscrita en la preocupación así sentida por la educación del príncipe, que en ese momento tenía catorce años con una especial inquietud por su desconocimiento del latín. ${ }^{19}$ Como bien ha mostrado Gonzalo Sánchez-Molero en su imprescindible Felipe II. La educación de un "felicisimo príncipe" (1527-1545) su educación formaba parte de un interés común.

Gonzalo Sánchez-Molero ha defendido la autoría de fray Juan de Valladolid, jerónimo del Monasterio de Guadalupe, basándose en la atribución documentada de la obra en el catálogo de la "librería riquísima" de Felipe II. ${ }^{21}$ A lo que sumar un encuadrado histórico posible, basado en la excelente ilustración del impulso llevado a cabo por el "cenáculo humanista toledano-complutense" 22 del que Juan de Valladolid podría formar parte por su vínculo con Francisco de Bobadilla y Mendoza.

La obra, sin embargo, ha sido atribuida mayoritariamente por la crítica a fray Miguel de Salinas de manera estable. El principal dato es la mención que de su autoría hace "Luys Gutierrez librero, al christiano lector" en 1563 al dar a la imprenta el Libro apologético que defiende la buena y docta pronunciación. ${ }^{23}$ Sabemos de Miguel de Salinas

18 "No sé si este aserto es otro topos de la humildad (con los que está lleno su prólogo) o si refleja un hecho verdadero. La dedicatoria algo inesperada al futuro Felipe II hace pensar en la posibilidad de que fuera el príncipe el personaje mencionado por nuestro fraile". Peter E. Russell, "Un libro indebidamente olvidado. La Rhetórica en lengua castellana (1541) de Fray Miguel de Salinas", en Libro-homenaje a Antonio Pérez Gómez, ed. Joaquín Pérez Gómez (Cieza: ... la fonte que mana e corre..., 1978), II, 133-142, 135.

${ }^{19}$ Sánchez García, "Introducción”, xvii-xix.

${ }^{20}$ Es en especial interesante para enmarcar la publicación de la obra, con independencia de la atribución de su autoría, y la constatación de la hipótesis formulada por Russell, el apartado dedicado por José Luis Gonzalo Sánchez-Molero a "La visita a la Universidad de Alcalá (1540) y su repercusión", Felipe II. La educación de un "felicísimo principe" (1527-1545) (Madrid, Consejo Superior de Investigaciones Científicas - Ediciones Polifemo, 2013), 441-490.

${ }^{21}$ Como señala Gonzalo Sánchez-Molero: "Se trata del ejemplar regalado al príncipe” y aunque aparezca referenciado bajo la autoría de fray Miguel de Salinas, añade entre paréntesis "En los inventarios escurialenses, atribuida a cierto fray Juan de Valladolid”, José Luis Gonzalo Sánchez-Molero, La "librería rica" de Felipe II. Estudio histórico y catalogación (San Lorenzo del Escorial: R.C.U. "Escorial-M" Cristina", Servicio de Publicaciones, 1998), 690. También, y al respecto de la autoría ha surgido otra propuesta, la de Juan Luis Vives, sostenida por Francisco Calero Calero, Juan Luis Vives o Fray Miguel de Salinas. A propósito de la Rhetórica en lengua castellana (Madrid: Fundación Universitaria Española, 2008). A nuestro parecer, los argumentos esgrimidos pertenecen a una tradición común, a lo que sumar que la originalidad del enfoque retórico de Vives, poco tiene que ver con la canonicidad de la Rethorica en lengua castellana.

${ }^{22}$ Gonzalo Sánchez-Molero, Felipe II, 445.

${ }^{23}$ Miguel de Salinas, Libro apologetico que defiende la buena y docta pronu[n]ciacio [n] q[ue] guardaro[n] los antiguos en muchos vocablos y accentos, con las razones que tunieron y ay para se tener, que fue buena y sabia y no ignorante ni mala segu $[n]$ que algunos delos modernos ha $[n]$ reprehendido y condenado (Alcalá de Henares: Casa de Pedro Robles y Fra[n]cisco de Cormellas, 1563). Con respecto a las teorías ortográficas y, en general, sobre los aspectos teóricos, y ante todo prácticos, que se desprenden del tratado, son muy interesantes las apreciaciones de Dolors Poch Olivé, "La buena y docta pronunciación según Miguel de Salinas", eds. Emilio Montero Cartelle y Carmen Manzano Rovira, Actas del VIII Congreso Internacional de Historia de la Lengua Española (Santiago de Compostela: Meubook-Asociación de Historia de la Lengua Española, 2012), II, 1753-1764, así como, y con respecto a la prevalencia del uso: Carlos Moriyon Mojica, "Valdés y Salinas. Dos actitudes frente a la lengua", Estudios de Lingüistica. Universidad de Alicante, 5 (1988-1989): 
principalmente gracias a la Historia de la Orden de San Gerónimo, compuesta por fray José de Sigüenza y publicada en Madrid, por la Imprenta Real, en $1605 .{ }^{24}$ Como apunta Gonzalo Sánchez-Molero, no se hace mención de la autoría de la Rhetórica en lengua castellana. Fuera por proteger al autor, preservando la autoría, o fuera por el conocimiento de Sigüenza de que la obra no pertenecía al autor, como señala Gonzalo Sánchez-Molero, ${ }^{25}$ cabe una tercera posibilidad. La ausencia de mención puede ser perfectamente justificable desde el contexto de dedicación religiosa al que apunta Sigüenza:

Hasta en los acentos y en la manera de leer en el refectorio no permitia descuido, y ansi compuso dos libros desto, que andan por ahi, y en el vno, que es de los acentos, descubre mucha lecion y se echa de ver que si empleara el ingenio en otro sugeto más graue lo hiziera bien. ${ }^{26}$

Sigüenza parece referirse al Tractado para saber bien leer y escrevir, pronunciar, cantar letras assi en latin como en romance (Zaragoza, 1551) y al Libro apologetico que defiende la buena y docta pronuciación (Alcalá de Henares, 1563) ${ }^{27}$ con los que la Rhetórica, no obstante, contiene más de un vínculo, como veremos más adelante.

También, y de ser cierta la dedicatoria al futuro Felipe II, existen circunstancias históricas que pudieran enmarcar una iniciativa semejante para el caso de Salinas. En la semblanza que de él ofrece Sigüenza hay datos reveladores, como el desempeño como maestro de novicios durante treinta y cinco años, ${ }^{28}$ el subrayado de sus capacidades persuasivas y la pertenencia al Monasterio de Santa Engracia. Como indica Encarnación Sánchez García, la documentación sobre su biografía lo señalan como una "figura clave" en un momento histórico en el que

291-301 y Abraham Esteve Serrano, "Contribución al estudio de las ideas ortográficas en España”, Tonos. Revista electrónica de estudios filológicos, XIII (2007): https://www.um.es/tonosdigital/znum13/secci ones/relecturas A ideas.htm (consultado el 8 de enero de 2021).

${ }^{24}$ Fray José de Sigüenza, Historia de la orden de San Jerónimo (Madrid: Bailly Baillière e Hijos, 19071909), 2 vols., II, 346-347.

25 Tal y como observa Gonzalo Sánchez-Molero: "Sobre esta cuestión también debían estar plenamente informados los jerónimos de El Escorial, en especial su bibliotecario fray José de Sigüenza. Para los defensores de que el autor fue fray Miguel de Salinas sorprendía que Sigüenza -quien dedica un largo y elogioso espacio a este compañero de profesión jerónima en su Tercera parte de la Historia de la Orden de san Geronimo (Madrid, 1605, p. 450) - no citara la Rhetórica entre sus obras. En nuestra opinión no le atribuía dicho libro -como algunos contemporáneos ya hacían- porque conocía perfectamente quién era el verdadero "progenitor" del libro.", J. L. Gonzalo Sánchez-Molero, "Fray Juan de Valladolid (OSH): lector del Novum instrumentum de Erasmo y autor de la Rhetórica en lengua castellana (1541)" en Grandes y pequeños de la literatura medieval y renacentista, coord. Emilio Blanco (Salamanca: Universidad de Salamanca, Sociedad de Estudios Medievales y Renacentistas (SEMYR), 2016), 307-331, 321.

26 Sigüenza, Historia, 346.

27 Sánchez García, "Introducción”, vii-viii.

${ }^{28}$ Como apunta Antonio Martí refiriéndose al total de la obra conservada y atribuida: "Tiene varias obras, todas de tipo literario y gramatical, que sin duda compuso pensando en los novicios que la Orden le había encomendado.", La preceptiva retórica española en el Siglo de Oro (Madrid: Gredos, 1972), 90. Por otra parte, y para la preocupación - en general - por la lengua vernácula en la enseñanza de la Retórica, véase José Rico Verdú, La retórica española de los siglos XVI y XVII (Madrid: CSIC, 1973), 48-50. 
[...] el convento era un escenario importantísimo de la actividad política del Emperador: En Santa Engracia se alojaba Carlos V cuando pasaba por Zaragoza y entre las paredes del monasterio encontraba personajes del valor del General de la Orden Pedro de la Vega, traductor de Tito Livio, o de Juan Regla, que llegará a ser confesor del Emperador y de Felipe II. ${ }^{29}$

No en vano Sigüenza dedica un capítulo a "La memoria del Padre fray Pedro de la Vega, fray Iuan Regla y fray Miguel de Salinas, professos de santa Engracia de Zaragoça", citado arriba, con un amplio tratamiento de la figura y de la influencia histórica de Juan de Regla y enlazando sus trayectorias vitales desde el enmarcado narrativo constante que guía su obra.

Con respecto a la atribución de la autoría de Juan de Valladolid, además de los argumentos esgrimidos por su valedor, nos cabe añadir otros dos que, hasta donde hemos podido ver, no han sido contemplados. En primer lugar, también existe una mención a un fray Juan de Valladolid en la Historia de la Orden de San Gerónimo. En ella se le retrata como "hombre de gran habilidad y talento", se subraya su cercanía al poder e incluso se apunta a que "han quedado algunos monumentos de su ingenio" $30 \mathrm{y}$, como en el caso de Salinas, tampoco se hace referencia a su autoría. En este sentido es de notar la coincidencia o no de la referencia a los monumenta que hace Juan Pérez de Toledo, Petreius, refiriéndose a las traducciones en la epístola en latín que antecede la Rhetórica en lengua castellana. ${ }^{31} \mathrm{Si}$ fue casualidad o no lo fue, tampoco, como en el caso de Salinas, se incluye referencia a su posible autoría.

En segundo lugar, un argumento que tampoco ha sido esgrimido, hasta donde hemos podido ver, para autorizar la autoría de Juan de Valladolid, es la mención

${ }^{29}$ Sánchez García, "Introducción”, ix y para los datos biográficos, vi-xii.

${ }^{30} \mathrm{Si}$ es cierta la identificación realizada por Sigüenza, al menos por el vínculo establecido con Francisco de Bobadilla y Mendoza, así se lee el recuerdo de su figura a propósito de fray Francisco de Santa María tras su llegada a España después de haber acudido al Concilio de Trento, y en concreto de su llegada a Segovia en 1559: "Buelto a España, el Rey don Felipe segundo le promouio a la Iglesia de Segouia, donde fue sumamente amado y querido de todos, hasta oy le lloran y echan menos. Contome vn religioso del Parral, vna cosa que vio el por sus ojos. Trahia en su compañia, y como por administrador ó mayordomo de toda su casa, vn religioso de Guadalupe, hombre de gran habilidad y talento: llamauase fray luan de Valladolid, que tambien gouerno algun tiempo el Obispado de Burgos por el Cardenal de Mendoça, y han quedado algunos monumentos de su ingenio. Assentó casa a nuestro don Francisco, y como le pusiesse vnas sillas de terciopelo, el santo varon, que no auia perdido aquella humildad santa que concibio en su alma quando recibio el habito de la religion, miró las sillas y miró su habito de paño pardo grossero, y pesandole de lo que via, dixo: no vienen bien, padre fray luan, estas sillas con este manto, y sino le fuera a la mano el religioso, estuuo con determinacion de darlas a pobres." Sigüenza, Historia, 315.

31 "Quicunque in scribendo operae precium aliquod sese facturos sperant, necesse est, vt aut illi noua afferant in tanta scriptorum turba, aut rudem vetustatem dicendo superent, aut vtroque praecellant, vel inuentorum nouitate, vel scribendi nitore atque elegantia. Praeter hos et illi mihi iure laudandi videntur, qui ex aliis in alias linguas doctorum hominum monumenta transfundunt, et has quasi nundinas et commercia literarum exercent." Salinas, Rhetórica, 7. 
concreta del Monasterio de Guadalupe, en el apartado que lleva por título «Síguese una forma para poner por exercicio las reglas de la rhetórica passada»:

Exemplo de lo primero sea esto: yo quiero, porque se me offresció al pensamiento por mi solo natural o por alguna cosa que se atravesó, escrevir la materia del monesterio de Guadalupe con todas sus particularidades, o alabar la vida y estado de la religión, o vituperar la guerra, o persuadir una hermana mía que críe con su propia leche un niño que parió. ${ }^{32}$

Pudiera ser un ejemplo posible propuesto por Salinas, incluso en homenaje a Pedro de la Vega, quien pasó parte de su infancia y de su juventud en Guadalupe ${ }^{33}$ para eludir la mención de su propio monasterio y evitar así la identificación de la autoría. También es posible pensar que fuera mención propia de Juan de Valladolid, sugiriendo internamente la autoría de la obra. Cabe así mismo una tercera posibilidad, la de que la mención al Monasterio de Guadalupe fuera el motivo último de la atribución de la obra a Juan de Valladolid por los bibliotecarios de El Escorial. Es algo que desconocemos pero que, junto a la mención no señalada previamente de la presencia de un Juan de Valladolid en la Historia de la orden de San Jerónimo, debería ser tenido en cuenta.

Por otra parte, creemos que merecerá la pena confrontar en un futuro, al menos, el Libro apologético y el Tractado para saber bien leer y escrevir con la Rhetórica en lengua castellana de una forma sistemática. Bien es cierto que el género es muy distinto, pero también existen rasgos internos que parecen apuntar a una autoría común y siempre en la misma dirección: una voluntad pedagógica absoluta, un deseo de remediar la falta de latinidad y, en último término, una insistencia teórica, en concreto sobre la pronunciación, que se destaca en la Rhetórica, pero que está avalada teóricamente, con un énfasis marcado, tanto en el Libro apologético como en el Tractado para saber bien leery escrevir. Son tres relieves aparentemente diferentes, si no fuera por la confluencia a la hora de abordar aspectos profundamente comunicativos.

El interés de la inclusión en la Rhetórica de la composición y del "ayuntamiento" de palabras en el apartado dedicado a la elocutio, ha sido subrayado por la crítica como una propuesta inserta en el abordaje del numero oratorio. ${ }^{34} \mathrm{El}$ predominio de la sonoridad del discurso en terrenos cercanos a los de la poesía, ${ }^{35}$ así como la insistencia

32 Salinas, Rhetórica, 150.

33 "El primero, que fue el padre fray Pedro de la Vega, de tierra de Burgos natural, siendo de treze años le lleuaron, o el se fue, no se porque ocasion, a nuestra Señora de Guadalupe, donde aprendio Gramatica con buen cuydado. De alli, siendo moço de diez y nueue años, se fue a nuestra Señora de Prado, a pedir el habito." Sigüenza, Historia, 342.

${ }^{34}$ Russell ya anotó la importancia de este apartado como uno de los consejos prácticos ofrecidos por Salinas, "Un libro", 137. Para una reflexión y una contextualización histórica, véase Ma Luisa López Grigera, La retórica en la España del siglo de oro. Teoría y práctica (Salamanca: Ediciones de la Universidad de Salamanca, 1994), 69 y Alfonso Martín Jiménez, Retórica y Literatura en el siglo XVI. El Brocense (Valladolid: Universidad de Valladolid, 1997), 104.

35 "Ansí como los que escriven en copla miden los pies hasta cierto número, porque de otra manera dissonaría, assí en la prosa, pues tiene su cierto número, se deven mirar a lo menos al buen oído.”, 
en que prevalezca el uso y no tanto la autoridad de otra lengua, ${ }^{36}$ como que sea el oído el último consejero o - "que cada uno se aconseje con su oído" ${ }^{37}$, son los argumentos principales que se desplegarán en el Libro apologético como el principal criterio a efectos de la pronunciación docta, ${ }^{38}$ y se verán contemplados también en el Tractado para saber bien leer y escrevir, siempre desde la autoridad de Cicerón y de Quintiliano. ${ }^{39}$

Es, por otra parte, una de las tres cualidades que señala el librero Luis Gutiérrez para encarecer la Rhetórica en lengua castellana, refiriéndose precisamente a la "pronunciación" como factor clave a destacar, no sin antes diferenciar netamente los campos respectivos de los que cada obra se ocupaba:

[...] no solamente en Filosofía y Teología según que claramente nos muestra, y en la arte oratoria, en que no sin grande ingenio, erudición, y común provecho escribió un libro harto conveniente y necesario, de la arte Rhetórica en castellano: donde trata alta y elegantemente de las partes del orador y arte Rhetórica, de la potencia y efecto de la elocuencia; y de la pronunciación Rhetórica. Aquí en este libro intitulado: libro de la

Salinas, Rhetórica, 125. En el Libro apologético puede leerse reiteradamente una constante reflexión sobre este principio y la comunicación constante entre la prosa y el verso, y no sólo a efectos de la pronunciación docta, por ejemplo, "Item primero hablaron los hombres en prosa que en verso, y conforme a la cantidad que se daba en prosa, se pasaba al verso." Libro apologético, 30 y ss. No deja de ser inspiración tomada del Orator, en su defensa del ritmo auditivo desde una base tan sólida como natural (Cicerón, Orator, LIII, 177-178) y propia tanto de oradores como de poetas y, en definitiva, de cualquiera que hable, verum omnino loquentium, Cicerón, Orator, LIII,177-178.

36 "De la orden, demás de lo dicho, es bien mirar que por guardar la gramática de la lengua latina o la propiedad de otra lengua, no se pervierta la orden. En verso paresce que tiene escusa, pero Don Enrique de Villena no la tendría tal, que usaba en sus cartas: "una vuestra rescebí letra" y otras cosas que guardavan más la orden latina que la castellana, y aunque la gramática fuesse buena es de mirar que concierten las palabras unas con otras y rueden bien." Salinas, Rhetórica, 125. En el Libro apologético, por ejemplo, incluso desde la tabla se señala "Una cosa es hablar latinamente, y otra gramaticalmente", con ilustraciones como las que siguen: "Los que comenzaron y continuaron a quebrantar la habla y pura ortografía de romance (fueron según tengo para mî) los muy latinos españoles, y los grandes latinos no naturales españoles: porque como se dieron tanto al latín; y tenían hechos los oídos y forma de escribir a él, no podían apartarse del en muchos vocablos cuando pasaban a razonar y hablar y escribir en romance." 264.

${ }^{37}$ Salinas, Rhetórica, 126. La referencia a este criterio en el Libro apologético es constante como forma de discriminar la pronunciación adecuada desde un tratamiento retórico: "Cicerón dice: Lo primero que se ha de hacer es escoger los vocablos que suenen bien, el modo de las tales cosas nota el arte: pero esas orejas lo definen con sentido callado sin arte", Libro apologético, 90 y “[...] dice Quintiliano en otra parte: Las orejas muy bien juzgan de la composición de la oración: en la cual sienten las cosas cumplidas, y desean las faltas, y se ofenden con las ásperas, y se deleitan con las suaves." Libro apologético, 114.

${ }^{38}$ Tal y como apunta Dolors Poch Oliver y en referencia al Libro apologético, sin vincularlo con la Rhetórica: "Los criterios que Salinas estima fundamentales para decidir cuál debe ser la buena pronunciación de una lengua son el uso y la eufonía", "La buena y docta pronunciación", 1.755 y ss.

${ }^{39}$ Desde la autoridad explícita de Cicerón, puede leerse en el tratado: "La oraciôn debe aplazer al deleyte de los oydos. Por lo qual es razón que se tenga mucha cuenta con el oydo: porque es cierto; que el que bien lee; causa mucho contentamiento en los oyentes: y que el que mal, mucho tedio y enojo: porque así como el primero da con sabor y claridad el sentido de la letra: asi el segundo lo da con desgracia y confusión, cuanto el primero es digno de honra, cuanto el segundo de vituperio; [...]" Salinas, Tractado, A ii v - A iii r. Todo ello resaltado al margen: "Lib. 2. - Quintiliano. Lib. 1. - Quintiliano Insti. Orato. In de oratore ad brutum." 
docta pronunciación $[\ldots]^{40}$

Es de por sí innovador incluir en la Rhetórica la reflexión sobre la composición al final de la elocución y, desde luego, su tratamiento es sintomático de la peculiar sensibilidad hacia la "efigie auditiva" ciceroniana,${ }^{41}$ hacia la materialización, como tal, del discurso desde aspectos puramente prácticos y tan comprometidos con la propia lengua, como es la de su sonoridad, no solamente como árbitro para la pronunciación, también como índice de un buen uso oratorio.

A lo anterior es preciso sumar la decisión radical de alterar el orden del sistema expuesto, incluyendo en el marco de la Retórica, lo relativo al ars conscribendis epistolis. Práctica, por otra parte, común en lo que a la absorción teórica se refiere, pero decididamente original en la medida en que el manual va dirigido a quien lee y a quien escribe, sin distinción, y la materia tomada, o recopilada, se ajusta a este propósito. Lo que el manual ofrece es no sólo la posibilidad de reducir a artificio la lengua castellana, sino también la posibilidad de un arte, en último término, una técnica que permita regular y afianzar las situaciones que se precisen. Es el campo abierto que halla Salinas para ajustar la técnica en los términos teóricos que requiere su intento y en los inmediatamente prácticos proclamados en ese aviso «ante todo necesario», mencionado más arriba, sobre la necesidad de ajustar la práctica más allá del conocimiento de las reglas y a la medida de lo que la discreción requiera. En este sentido una de las grandes aportaciones de la obra, a nuestro parecer, es el tratamiento de las circunstancias. Salinas avisa en el Prólogo de la importancia que les concede:

$[\ldots]$ porque no teniendo cogidas en uno las circunstancias que se requieren para el bien hablar según la diversidad de las materias y tiempos y personas que oyen, muchas vezes no se ayudan dellas o, a lo menos, no de todas las que se podrían aprovechar, y assí, coxquean sin sentirlo ni saberlo remediar. ${ }^{42}$

Desde esta perspectiva, las circunstancias se erigen en las pautas posibles para el ajuste de la teoría retórica. Son las circunstancias propias que rodean al orador y a su discurso, dando un salto que ya dieron Cicerón y Quintiliano, de forma más extensa en el proyecto pedagógico y sistemático de la Institutio frente al abordaje lúcido y desprendido de la aproximación a la "elocuencia perfecta" del Orator ciceroniano. Ambos aluden a todo aquello que deba considerar el orador más allá del conocimiento del arte, no otra cosa que la experiencia cambiante de las circunstancias vitales a las que deba aplicarse. ${ }^{43}$

Lo que para la tradición clásica es perfectamente comprensible dada la utilidad obvia de la comunicación retórica en el contexto de lapolis, de la comunidad así regulada, se convierte en un verdadero obstáculo si lo que se pretende es recobrar la

\footnotetext{
40 Salinas, Libro apologético, $3 \mathrm{v}$.

41 [...] sic perfectae eloquentiae speciem animo videmus, effigiem auribus quaerimus, Cicerón: Orator, III, 10.

42 Salinas, Rhetórica, 11.

${ }^{43}$ Cicerón, Orator, 71, citado por Quintiliano como marco para el tratamiento del decoro, Institutio, $11,1,4$.
} 
Retórica desde el universo político y cultural que la sostuvo, un contexto por completo diferente y aislado en el tiempo. El afán pedagógico de Salinas, así como el ímpetu de ofrecer algo tan novedoso como una Rhetórica en lengua castellana que sea útil, implica una valoración desgajada de la tradición y una atención constante a esas circunstancias cuya novedad reside también en el alejamiento obvio de las que concurrieron en los tiempos considerados por la Retórica clásica.

En este sentido, y a nuestro parecer, la principal contribución de la Rhetórica en lengua castellana es que todas las consideraciones, desde el manual hasta los apéndices que lo ponen en práctica y lo completan, giran de una forma u otra sobre el eje de una mirada atenta a lo que sucede alrededor, a lo que es cambiante, como si el ofrecer una retórica en lengua castellana incorporara de suyo el necesario permiso para contemplar lo que en esa lengua y en ese tiempo se comunica. El impacto a efectos teóricos de esta convicción es considerable, si se tiene en cuenta la tradición de la que parte, hasta el punto de alterar la exposición del sistema retórico, siempre desde fuentes teóricas clásicas y coetáneas, pero aplicándolo hasta sus últimas consecuencias.

No resulta tópica la advertencia del propio autor en el Prólogo cuando avisa, como posible falta, del "ruin orden". ${ }^{44}$ Dado el carácter pedagógico, además de programático, del impulso de Salinas, lo que sorprende precisamente es la ordenación en la medida en que propone un plan perfectamente trazado. Si bien, en apariencia, la disposición de los preceptos de la Retórica es la canónica, Salinas incluye una interesante variación, profundamente significativa en la medida en que está destinada a alojar las circunstancias en el lugar preciso, aquel que activa el uso comunicativo de la Retórica. Para ello es definitiva la mención de los géneros contemplados desde los estados de la causa, no así del discurso retórico, y desde una lectura más que atenta del De conscribendis epistolis de Erasmo.

Al tratarse de una comunicación en ausencia del receptor, la consideración de las circunstancias cobra especial relieve desde la influyente formulación de las artes dictaminis medievales convenientemente transfiguradas en los modi epistolandi humanistas. ${ }^{45} \mathrm{Tal}$ y como señaló James J. Murphy, la importancia última de las artes

44 "No faltarían que tachar en todo ello, si se pusiesse en manos de quien lo uviesse gana, assí descuidos como ignorancias, o ser ruin orden, o poder ser mejor." Salinas, Rhetórica, 16.

45 Aunque la bibliografía en este punto es muy abundante, cabe destacar, a nuestro propósito, el trazado histórico desde el ars dictaminis al modus epistolandi bumanista, desde la mediación clásica, realizado por Marc Fumaroli "Genèse de l'épistolographie classique: Rhétorique Humaniste de la Lettre, de Pétrarque à Juste Lipse [with Discussion].” Revue D'Histoire Littéraire De La France, 78, 6 (1978): 886-905, así como la evolución desde la consideración sobre la complejidad de la materia epistolar contemplada en Claudio Guillen, "Para el estudio de la carta en el Renacimiento" en La epistola, ed. Begoña López Bueno (Universidad de Sevilla: 2000), 101-127. Son también muy interesantes las observaciones de Pedro Martín Baños, El arte epistolar en el Renacimiento europeo. 1400-1600 (Bilbao: Servicio de publicaciones de la Universidad de Deusto, 2005), con especial atención hacia la influencia ejercida por el tratado de Erasmo, así como por el trazado histórico del género, además del vínculo establecido por la perspectiva humanista desde la herencia clásica, tal y como puede leerse en Trinidad Arcos Pereira, "De Cicerón a Erasmo: La configuración de la epistolografía como género literario", Boletín Millares Carlo, 27 (2008): 347-400. Para el papel de la epístola en los Studia Humanitatis, con especial referencia a "la inclusión de la epístola en el currículum escolar" para el "caso español", véase Jamile Trueba Lawand, El arte epistolar en el Renacimiento español (Madrid: Támesis, 1996), 46 y ss. Es también ilustrativo el análisis del universo 
dictaminis medievales consiste en ser "un raro ejemplo de retórica aplicada" 46 , dictadas por la necesidad para acabar cobrando vida propia, una vida de la que se nutrió, para transformarlas y aclimatarlas, el arte epistolar renacentista. Como es sabido, es un género fundamental para el Humanismo con la aportación destacada de Erasmo y de su Opus de conscribendis epistolis publicado en Basilea, por Fröben, en 1522, tras un ajuste teórico de publicaciones anteriores sobre la materia. ${ }^{47}$

No menos interesante es el De conscribendis epistolis de Juan Luis Vives, de 1536, no sólo por estar dirigido al secretario real de Carlos V, Alonso de Idiáquez y Yurramendi, sino por la sistemática reflexión sobre las circunstancias excepcionales sobre las que la comunicación epistolar se fundamenta - "cuyo uso es grande para todas las circunstancias de la vida", ${ }^{48}$ desde la constante perspectiva de que "la carta es una especie de retrato o reproducción del habla cotidiana y una especie de diálogo continuado" 49 y desde los vectores constantes de la consideración de las circunstancias así como de la sutil jerarquía establecida por la posición sobrevenida de quien se dirige a otro:

Considere el que va a escribir una carta quién es al que escribe y a quién escribe y de qué materia; qué es él para consigo mismo, qué somos nosotros para con él; le somos desconocidos o conocidos, amigos o enemigos, amigos lejanos y dudosos, o declarados y estrechos, iguales o desiguales $[\ldots]^{50}$

Si bien la presencia del tratado de Vives no es tan contundente como la del de Erasmo, si creemos que merecerá la pena, más allá de los objetivos de este trabajo,

compuesto por la correspondencia desde los aspectos propios de su materialidad, de su aprendizaje y práctica en el universo humanista tal y como refiere Antonio Castillo Gómez, "Vos, señor, la escribiste a la luna'. Aprendizaje, discurso y prácticas epistolares en la España Moderna”, Estudios Filológicos, 60 (2017): 33-55 o desde la adscripción genérica según el uso al que se destinen: Pedro Martín Baños, "Familiar, retórica, cortesana: disfraces de la carta en los tratados epistolares renacentistas", Cuadernos de Historia Moderna. Anejos, 4 (2005): 15-30.

${ }^{46}$ Es una de las conclusiones a las que llega James J. Murphy en el imprescindible capítulo "Ars dictaminis. El arte epistolar" en su La Retórica en la Edad Media. Historia de la teoría de la retórica desde San Agustin hasta el Renacimiento, trad. G. Hirata Vaquera (México D. F.: Fondo de Cultura Económica, 1986), 202-274, 274.

${ }^{47}$ Con respecto a la génesis teórica del de De conscribendis epistolis de Erasmo han de ser tenidas en cuenta las consideraciones realizadas por Judith Rice Henderson, "The enigma of Erasmus' Conficiendarum epistolarum formula", Renaissance and Reformation / Renaissance et Réforme, 25, 3 (1989): 313-330, así como el análisis de la evolución teórica en términos de un alejamiento de la tradición ciceroniana en Judith Rice Henderson "Erasmian Ciceronians: Reformation Teachers of Letter-Writing", Rhetorica. A Journal of the History of Rhetoric, 10, 3 (1992): 273-302, 277-280. Son así mismo necesarias las precisiones textuales que figuran en la "Introduction" de Jean-Claude Margolin, para la edición por la que citaremos, Erasmo de Rotterdam, "De conscribendis epistolis", ed. Jean-Claude Margolin, Opera omnia Desiderii Erasmi Roterodami. Recognita et adnotatione critica instrvcta notisqve illustrata. Ordinis primi Tomvs secundvs (Amsterdam: Nort-Holland Publishing Company, 1971), 204-579, para la introducción: 157-204.

48 Juan Luis Vives, "Redacción epistolar (De conscribendis epistolis)" en Obras completas, ed. Lorenzo Riber (Madrid: Aguilar, 1947-1948), 2 vols., t. I, 841-879, 841.

49 Vives, "Redacción", 868.

${ }^{50}$ Vives, "Redacción”, 843 a lo que sigue una amplia enumeración de posibilidades a tener en cuenta. 
observar su posible influencia, al menos por lo que corresponde a la reflexión sobre la jerarquía realizada por Vives para explicar el género y por la atención de Salinas, siempre contando con los lugares tópicos del arte epistolar, por determinar la posición - superior o inferior - del que requiere o del que es requerido. El enfoque de Erasmo es mucho más teórico y esquemático, es el lugar idóneo desde el que movilizar lo que pretende Salinas.

Desde la perspectiva de la Retórica volcada en la oratio, puede comprenderse la contribución única de Erasmo en su De conscribendis epistolis, cuando salvó el principal escollo al que, por otra parte, la propia Retórica se había enfrentado desde su origen; aplicar la teoría clásica sobre los géneros del discurso a la comunicación coetánea. Desde este punto de vista la consideración teórica del género forense, del género deliberativo y del género demostrativo era más que difícil, por mucho que se intentara hallar caminos de adecuación.

El trazado teórico de Erasmo es impecable. Se detiene, como por otra parte era habitual y propio del género que trata, en las formas de saludo y despedida, es decir, en las formas de materializar, en la medida de lo posible, la ausencia del destinatario. Al amplio tratamiento debido a "De salvtatione" ${ }^{51}$ le sigue el "De ordine epistolari", 52 desviándose del trazado rígido del dictamen medieval y avisando, de entrada, de las múltiples posibilidades abiertas - Ordinem in epistolis, vel a natura, vel ab arte licebit petere, sed ab arte infrequentius ${ }^{53}$ - y como antesala deteniéndose en primer lugar en las epístolas mixtas. $^{54}$

Admitiendo la versatilidad del género y en última instancia de la clasificación, no obstante, a continuación abrirá el apartado para los "Epistolarvm genera" 55 al que destinará prácticamente el resto del tratado, ofreciendo para cada uno, desde sus múltiples posibilidades, una consideración teórica acompañada de ejemplos incluso propios, además de una colección de fórmulas posibles, extraídas de la tradición o bien propuestas por él mismo.

Salinas parte de un sistema retórico y, por más que las consideraciones erasmianas sean retóricas, no abandonan en ningún momento la obligación debida al arte epistolar. ${ }^{56}$ Sin embargo, Salinas parece ver la posibilidad de incluirlas, sin referirse no solamente a la procedencia, como por otra parte no hace con el resto de autoridades, sino ordenándolas en este caso a lo que le conviene. De ahí la alteración del orden en su exposición, de ahí quizá esa alusión al «ruin orden» al que nos referíamos más arriba. $^{57}$

${ }^{51}$ Erasmo, "De conscribendis", 276, 15 - 300.

52 Erasmo, "De conscribendis", 301-302.

${ }^{53}$ Erasmo, "De conscribendis", 301.

${ }^{54}$ Erasmo, "De conscribendis", 303-308.

55 Erasmo, "De conscribendis", 309.

${ }^{56}$ Henderson "The enigma", 326-327.

57 Así procede explícitamente Vives en su tratado, reordenando estructuralmente la materia: "Vamos a unir la invención del género epistolar con alguna parte de su disposición, especialmente en los exordios. Puesto que éstos con mucha frecuencia no pueden separarse fácilmente, idénticos son en determinadas ocasiones sus preceptos.", Vives, "Redacción”, 843. El tratamiento retórico que le dispensará Vives se detendrá especialmente en las fórmulas elocutivas. Para la importancia de la elocutio en la Retórica de 
En apariencia la Rhetórica en lengua castellana discurre por el orden establecido. Por lo que respecta a los géneros del discurso, transita principalmente por la autoridad de Nebrija, apoyada en la de Quintiliano, distinguiendo al principio del tratado la concurrencia de los tres grandes géneros, demostrativo, deliberativo y judicial, e incluso mencionando la impecable clasificación aristotélica según el receptor - juez o espectador - perpetuando la inveterada incomprensión de la división dual peripatética. ${ }^{58}$

El orden continúa en los estrictos términos de la tradición clásica, con la mención de las cinco partes artis explicándolas desde su integración, ${ }^{59}$ para seguir tratando cada una de ellas. En el amplio apartado destinado a la inventio ${ }^{60}$, Salinas distingue a su vez seis partes: «Y assí, dizen que son seis las partes de la oración: Exordio, narración, división, confirmación, confutación, conclusión», destacando al margen «Partes de la invención: o de la oración $n$, ${ }^{61}$ subrayando así su cualidad ambivalente con la referencia a la oratio y, en definitiva, a las partes orationis, o a la disposición que tratará brevemente a continuación de lo reservado a la inventio.

Así se detiene en el exordio ${ }^{62}$ y en la narración ${ }^{63}$ y es en el apartado destinado por la retórica a la divisio, o a la división, o al momento de adelantar la causa, ${ }^{64}$ al hilo

Vives y sus implicaciones últimas, véase Tomás Albaladejo, "Retórica y elocutio: Juan Luis Vives", Edad de Oro, XIX (2000): 9-28.

58 "Capítulo II. De tres géneros de causas en Rhetórica", Salinas, Rhetórica, 22-23. Para la incomprensión de la división dual peripatética, véase $\mathrm{M}^{\mathrm{a}}$ Amelia Fernández Rodríguez, Una idea de maravillosísima hermosura. Poética y Retórica ante la Lírica en el siglo XVI (Madrid: Ediciones de la Universidad Autónoma de Madrid, 2003), https://libros.uam.es/?press=uam\&page $=$ catalog\&op $=$ book\&path $\% 5 \mathrm{~B} \% 5 \mathrm{D}=76$

(consultado el 8 de enero de 2021): 54-67.

59 “Capítulo III. De las partes de la Rhetórica”, Salinas, Rhetórica, 24. Desde la integración de las partes y para el novedoso tratamiento que dispensa Salinas a la operación de memoria, véase Juan Carlos Gómez Alonso "Retórica y Poética en los siglos XVI y XVII: La operación retórica de memoria", Edad de Oro, XIX (2000): 121-130, 127. Para el tratamiento de la pronuntiatio, con especial atención a la "enseñanza a contrario", véase María Ángeles Díez Coronado, Retórica y representación. Historia y teoría de la Actio (Logroño: Instituto de Estudios Riojanos, 2004), 90.

60 Todo lo relativo a la inventio, o "invención”, comienza en el Capítulo IIII. De la invención (25-111) hasta llegar al tratamiento de la siguiente de las partes, ya en el Capítulo XXX. De la disposición o orden. (112-113). De la importancia concedida a esta parte frente a las demás da cuenta desde el comienzo mismo de su tratamiento: "Invención es pensar cosas verdaderas o verisímiles con que lo que inventa el que habla parezca razonable. Entre las cinco partes de la rhetórica ésta es la más larga, la qual sabida, se tiene lo más del bien hablar. Y assí, comúnmente, hablando a alguno que habla bien, dezimos que tiene buena inventiva.", 25. De la extensión de la inventio, a la par que en el caso de Nebrija, advierte Luis Alburquerque García, "La vuelta a la Retórica y el Humanismo español (acerca de la inventio)", Actas del XI Congreso de la Asociación Internacional de Hispanistas. De historia, lingüísticas, retóricas y poéticas, coord. Juan Villegas (Madrid: Asociación Internacional de Hispanistas, 1994), I, 148-154, 148-149. Por otra parte, para la importancia concedida a la inventio frente a la elocutio, véase Francisco Vicente Gómez, "La tensión inventio-elocutio en la Rhetórica en lengua castellana de Miguel de Salinas", en Los Humanistas españoles y el Humanismo europeo. Actas del IV Simposio de Filología Clásica (Murcia: Servicio de publicaciones de la Universidad de Murcia, 1990), 255-260.

${ }^{61}$ Salinas, Rhetórica, 25.

62 "Capítulo V. Del exordio", Salinas, Rhetórica, 26-30.

63 "Capítulo VI. De la narración”, Salinas, Rhetórica, 31-45.

64 "Capítulo XIII. De la división”, Salinas, Rhetórica, 46-48. 
de la autoridad de Nebrija y en último término de Quintiliano, en el que introduce la mención a los géneros, convertidos como tal en géneros sobre el estado de la causa, y no en fuentes o cauces para la composición de cartas, a la manera, como veremos, de Erasmo.

La decisión de Salinas de tratar canónicamente la inventio es particularmente acertada, en aras de la claridad expositiva y de la función práctica que guía el tratado. Es este el punto desde el que parte Salinas para su tratamiento de la inventio, antecediendo la información reservada al exordio y a la narratio, como elementos comunes a cualquier comunicación, sea por otra parte oral o escrita. En este sentido, y en especial para la narratio, quedarán previamente establecidas las "circunstancias de la persona" y "las circunstancias del lugar, tiempo y de las otras cosas", a las que remitirá continuamente en el apartado siguiente, modelando las situaciones comunicativas que se requieran. ${ }^{65}$

De esta forma no es necesario, como en el caso del De conscribendis epistolis, singularizar cada modelo posible, era una exigencia en definitiva de la materia sobre la que Erasmo trata. Salinas, integrándola en una retórica a todos los efectos, fusionará lo debido a la aplicación de la causa y de sus estados ${ }^{66}$ a los tres géneros del discurso con las tres omnium generum fontes propuestas por Erasmo en un abordaje integral, tan profundamente complejo como compleja es, por su naturaleza, la materia que trata.

El trazado de las líneas realizado por Erasmo se ordena desde la gran división sobre los tres géneros retóricos, incluso sumando uno más, el familiar. Todo ello bajo el rótulo de "Tres omnivm genervm fontes" aludiendo desde la canonicidad del sistema retórico a que no son géneros como tal, sino fuentes desde las que se nutre la multiplicidad de los asuntos posibles de una carta:

Rhetorum plerisque tria causarum genera placuerunt, suasorium, encomiasticon et iudiciale. Ad haec tanquam ad fontes pleraeque literarum formae referuntur, vt suasorio has fere partes subiicias: conciliationem, reconciliationem; exhortationem,

\footnotetext{
${ }^{65}$ Son los capítulos "Capítulo VII. De las circunstancias de la persona" y el "Capítulo VIII. De las circunstancias del lugar, tiempo y de las otras cosas", Salinas, Rhetórica, 34 y 35 que sirven como introducción para un tratamiento más amplio. Para el perfilado teórico y el análisis de las fuentes, véase Elena Artaza, El ars narrandi en el siglo XVI español. Teoría y práctica (Bilbao: Universidad de Deusto, 1989), 186-195. Sobre la modernidad del planteamiento de Salinas en este punto, véase Ascensión Rivas Hernández, "Miguel de Salinas, la retórica y la Modernidad", eds. Antonio López Eire, Juan Miguel Labiano Ilundain y Antonio M. Seoane Pardo, Retórica, política e ideología. Desde la Antigüedad hasta nuestros dias. Actas del II Congreso Internacional (Salamanca: LOGO: Asociación Española de Estudios sobre Lengua, Pensamiento y Cultura Clásica, 1998), II, 47-52. Por su parte, Luis Alburquerque García señala que la originalidad de la Rhetórica no sólo radica en estar escrita en castellano, sino en que "adapta las circunstancias a las necesidades de su tiempo" y resalta, para el tratamiento de la narratio, la perspectiva teórica de Salinas al insistir en su cualidad de ser una forma de amplificación y un medio para conferir "plasticidad" al discurso. El arte de hablar en público. Seis retóricas famosas del siglo XVI (Nebrija, Salinas, G. Matamoros, Suárez, Segura y Gużán) (Madrid: Visor, 1995), 62 y 105-106.

${ }^{66}$ El capítulo XIII titulado "De los estados", recoge la siguiente definición: "Muchísimos sientan tres estados de causa general, de conjetura, de definición y de cualidad. De éstos se vale Cicerón en su Orador, y dice que a ellos se reduce todo cuanto se pone en cuestión, verbigracia: Si existe la cosa, qué es la cosa y cómo es la cosa", Salinas, Rhetórica, 50.
} 
dehortationem; suasionem, dissuasionem; consolationem, petitionem, commendationem, monitionem, amatoriam. In demonstratiuo genere versantur descriptiones, personarum, regionum, praediorum, arcium, fontium, hortorum, montium, monstrorum, tempestatum, itinerum, conuiuiorum, aedificiorum, pomparum. Ad iudiciale genus, haec fere referuntur: Accusatio, querela, defensio, expostulatio, expurgatio, exprobatio, comminatio, inuectiva, deprecatio. His tribus quartum genus accersere licebit, quod si placet, familiare nominemus. ${ }^{67}$

El acopio que hará Salinas del De conscribendis epistolis no es sólo estructural, vertebra cada uno de los modelos posibles, evitando cualquier referencia a que se trate de epístolas y absorbiéndolos en la faceta doble de quien habla y de quien escribe. Siguiendo Salinas el cauce de la Retórica y remitiendo en todo momento a la clasificación y descripción inicial de los géneros del discurso, así como al exordio y a la narración, integrantes de la inventio, los encuadra en el horizonte de las circunstancias comunicativas. Así el capítulo decimonoveno «Del genero demostrativo» se abre de la siguiente forma, con la alusión debida al laus y vituperio y sintetizando la extensa nómina de posibilidades abiertas por Erasmo para el género demostrativo - encomiástico -:

El género demostrativo se parte en dos partes principales, según está dicho. En demostrar, o enseñar, o dar cuenta de alguna persona, lugar, tiempo o otra cosa en general. Y quanto a esta parte lo que allende de lo que está dicho se puede dezir, es que siempre se procure que sea muy al natural, para lo qual en todo remito a lo que está dicho hablando de la narración. La otra parte se exercita en alabar o vituperar algo, y en esto, como en todo lo demás, es muy necessario mirar todas las circunstancias de la cosa que se trata según están puestas atrás. ${ }^{68}$

El capítulo vigésimo "Del género deliberativo" se define desde el territorio propio de la persuasión y acogerá a la exhortación, a la petición y a la consolación, obviando la especie amatoria o una forma tan asentada como la de la carta comendaticia. Debido a la interacción requerida, más expuesta que en el caso anterior, no es extraño que se insista una vez más en las circunstancias de la manera siguiente:

${ }^{67}$ Erasmo, "De conscribendis", 310, 14 - 311, 9. Como indica J. R. Henderson ya de manera temprana en la Formula "He was developing the more sophisticated definition of the genre we find expressed in the later versions of the treatise. The Formula works toward the synthesis of medieval and classical traditions of letter- writing achieved in the Opus de conscribendis epistolis.", "The enigma", 5. Para las fuentes griegas presentes en la enumeración posterior que da cuenta de la tradición clásica helenística, véase la tercera nota que le dedica John Monfasani, "Three Notes on Renaissance Rhetoric", Rhetorica, 5, 1 (1987): 107-118, 115-118. Juan Luis Vives, por su parte, sigue la tradición ciceroniana sin forzar, desde la teoría sobre la oratio, la teoría retórica, y ciñéndose a dos géneros de cartas "uno, el género familiar y festivo; otro, el serio y grave.", "Redacción", 842. De hecho, como indica J. R. Henderson, evita explícitamente no sólo una clasificación sobre los géneros del discurso, sino también un enfoque desde las partes artis y desde la partes orationis. "Defining the Genre of the Letter Juan Luis Vives 'De Conscribendis Epistolis", Renaissance and Reformation / Renaissance et Réforme, 7, 2 (1983): 89-105, 101.

${ }^{68}$ Salinas, Rhetórica, 65. 
En el género deliberativo o suasorio háse de tener primeramente cuidado de mirar qué sea y de qué qualidad lo que queremos persuadir, y quiénes sean los que oyen, y quiénes somos los que hablamos. ${ }^{69}$

En este punto se acoge Salinas a la cuidadosa matización de Erasmo incluyendo la exhortación, cuando en el De conscribendis epistolis se dedica un apartado, tras la exposición de las tres omnium generum fontes, a "Qvid inter exhortationem et svasionem." 70 Salinas la asimilará con la licencia debida y a su propósito, encabezando la reflexión sobre la exhortación ${ }^{71}$ como un marco más amplio, propio del género deliberativo, con el que culminará más adelante su tratamiento, adelantando lo que habrá de seguir, la petición y la consolación:

Aunque sean quasi una cosa con el género suasorio las otras especies que a él se refieren (porque el que consuela amonesta que suffran con paciencia, el que reprehende amonesta que se conozca la culpa y aya enmienda, etc), pero por mayor abundancia, demás de lo que he dicho, quiero añadir algo de las otras partes y no de todas por no detenerme mucho, mas sólo de la consolación y petición que se offrescen muchas vezes. ${ }^{72}$

El tratamiento que Salinas dispensa a la Exhortación ocupará el capítulo XXI de su manual, siguiendo ya lo relativo al De exhortatoria epistola de Erasmo, en especial en lo referente a los lugares que han de convocarse:

Ergo ex his potissimum locis extimulandi animi rationes petemus. A laude, spe, metu, odio, amore, miseratione, aemulatione, expectatione, exemplis, obsecratione. ${ }^{73}$

En este caso Salinas resumirá lo allí dicho y vertebrará el tratamiento sobre la exhortación desde la "esperanza" y la obtención de "galardón y provecho", pero seguirá atentamente la pauta de Erasmo integrándola en su propio discurso. ${ }^{74}$

Como ejemplo del procedimiento seguido por Salinas en su lectura y copia más que atenta de la obra de Erasmo, valga la forma en la que trata "De la petición" - ${ }^{75}$ a

\footnotetext{
${ }^{69}$ Salinas, Rhetórica, 68.

70 “Ac primum finitimae admodum inter se sunt, exhortatio, et suasio, quas nos tamen dicendi gratia separauimus; idque fecimus neque sine exemplo, neque citra iudicium, propterea quod et veterum nonnulli in arte dicendi, exhortatorium genus a deliberatiuo disiunxissent, et ipsi nonnihil discriminis perspiceremus. Siquidem nec eoden tendit vtrunque, neque via simili. Nam suadendo id agitur, vt velis; exhortando, vt audeas." Erasmo, "De conscribendis", 315, 8-13.

71 "Ay differencia de amonestar que alguno quiera cosa que no le paresce, o duda que se deve querer, que en latín se dize suasio, lo qual se haze probando las partes dichas o algunas dellas; o de poner ánimo a los que han començado a seguirlo, pero o cessan o lo hazen floxamente, que se dize exhortación, que aunque sean semejante cosa, no del todo. El que suade muda el propósito o procúralo mudar; el que exhorta no le muda, mas pone ánimo para ponerlo por obra." Salinas, Rhetórica, 72.

${ }^{72}$ Salinas, Rhetórica, 75.

${ }^{73}$ Erasmo, "De conscribendis", 324, 14-16.

${ }^{74}$ Salinas, Rhetórica, 72-75.

75 Salinas, Rhetórica, 79.
} 
la que dedica el capítulo XXIII. Lo que desde el arte epistolar se puede considerar como una parte orationis, en el sentido de aquello que se pide y solicita, puede ser también un modelo en sí, con sus propias claves, en el caso de que se convierta en asunto de la carta. En la Rhetórica puede leerse convenientemente extractado y ampliado el tratamiento que le da Erasmo a la "De petitoria epistola". Las pautas seguidas por Salinas para la aclimatación del texto pasan por eliminar cualquier referencia a los ejemplos ${ }^{76}$ por la acomodación a la propia realidad comunicativa y por aligerar la información, remitiendo, además, al diseño de su propio manual.

En comparación con el De conscribendis epistolis erasmiano, el tratamiento dispensado a la petición por Salinas es significativamente breve y está integrado en la estructura de la Rhetórica. Erasmo discurre en primer lugar por un tratamiento teórico y sumario que seguirá casi al pie de la letra Salinas variando lo necesario desde la perspectiva del trazado de su propia obra. Bajo el apartado de "De petitoria epistola", Erasmo define e introduce la materia. La contextualización inicial de Erasmo al comentario de Servio a la Eneida, se elimina en la Rhetórica, introduciendo directamente las cuatro circunstancias posibles que sustentan una petición:

Seruius enarrans locum, in libro Aeneidos primo, vbi Iuno supplex petit ab Aeolo vt classem Aeneae disiiciat, indicat praecipere rhetores in omni petitione quatuor seruanda esse: primum vt quod petimus ostendamus esse in potestate eius a quo petimus; praeterea $v t$ doceamus esse iustum quod petimus; deinde vt modum ac viam indicemus, qua confici possit, quod petimus; denique vt sequatur remuneratio. ${ }^{77}$

Mientras que Salinas elimina la contextualización preliminar, pero amplía y explica la información que de ello se deduce, siguiendo, no obstante, el desarrollo posterior de Erasmo y, con el procedimiento habitual, explicando cada punto y ajustándolo a sus intereses:

Si queremos pedir algo hánse de hazer quatro cosas. Lo primero mostrar que lo que pedimos es en poder de aquel a quien lo pedimos. Luego ser la petición justa, encaresciendo lo que va en ello. Después mostrar la manera cómo se puede hazer, mayormente quando creemos que se puede en ello dudar. Al cabo mostrar la remuneración señalando alguna cosa en especial o en general, offresciendo a nosotros mismos y a todas nuestras cosas, salvo si creemos que es bien notorio estar aparejada nuestra voluntad, o tememos que se podría rescebir affrenta en prometer retribución. Pero aún estos casos es bien tocarse lo que baste a entenderlo si quisieren, con offrescimientos generales o especiales en pocas palabras. ${ }^{78}$

\footnotetext{
${ }^{76}$ Como señala E. Sánchez García refiriéndose a su edición y al De copia en su artículo "Nebrija y Erasmo", 296: "El método usado por Salinas consiste en omitir la mayor parte de los abundantísimos ejemplos de la literatura clásica que Erasmo aportaba, o en sustituirlos por otros del mismo autor pertenecientes a un párrafo descartado".

77 Erasmo, "De conscribendis", 465, 9-13.

78 Salinas, Rhetórica, 79.
} 
Por lo que se refiere a la naturaleza de aquello que se pide, Salinas procede a la traducción directa del pasaje de Erasmo:

Primum, quoniam varia est natura rerum quas petimus; et magna est varietas personarum quae rogant, aut rogantur, oportet et petendi rationem esse variam. ${ }^{79}$

Y como las cosas que se pueden pedir son diversas y ay diversidad de los que piden y de los que son pedidos, assí la manera del pedir será diversa. ${ }^{80}$

Siendo así la antesala de una aplicación que abandona la clasificación interna elaborada por Erasmo y la reconducción, ya hacia la Rhetórica, del tratamiento de las circunstancias, A pesar de lo anterior con mínimas variaciones, pero significativamente intensas, añade ejemplos posibles que no remiten tanto a la teorización como a circunstancias previsibles, en el caso de la Rhetórica, por ejemplo, con la inclusión, además del consejo, de "la ayuda de oraciones":

Sunt enim quaedam, quae fauorabiliter petimus a quouis, veluti consilium; sunt quae pudore suffundunt rogantem, veluti quum petimus mutuum, aut rem parum honestam. ${ }^{81}$

Ay cosas que se piden sin rescebir por ello empacho, como es consejo y ayuda de oraciones. Otras con vergüença, como son dineros o cosas no lícitas y diffíciles de aver. ${ }^{82}$

Con respecto al tratamiento de estos dos posibles caminos, Erasmo introduce una clasificación teórica, entre aquello que se puede pedir abiertamente, o de forma recta, o aquello que exige una mayor elaboración, un proceder "oblicuo":

Igitur in genere duplex erit petendi modus, rectus et obliquus. Vbi causa erit fauorabilis, aperte suadebimus esse praestandum quod petimus; vbi secus, per insinuationem irrepemus in petitionem. ${ }^{83}$

Salinas retoma en este punto el procedimiento habitual, eliminando cualquier referencia teórica que no se ajuste al plan trazado en su Rhetórica-como es el de la distinción erasmiana presente en su tratado sobre la forma de proceder - para referirse como tal a la técnica, o arte, o a la carencia de ella:

Quando es cosa común y que sin empacho se suele pedir y es fácil de aver y lícita, no es menester arte, o poca, para ello. Basta considerar las quatro cosas arriba dichas o las más substanciales dellas. Si es cosa no lícita y que puede dar pesadumbre no se deve

\footnotetext{
79 Erasmo, "De conscribendis", 465, 19-21.

${ }^{80}$ Salinas, Rhetórica, 79.

${ }^{81}$ Erasmo, "De conscribendis", 465, 21-24.

${ }^{82}$ Salinas, Rhetórica, 79.

${ }^{83}$ Erasmo, "De conscribendis", 465, 24 - 466, 2.
} 
pedir assí a la clara, mas poner primero en quánta necesidad estemos y quán rezia cosa sea la necessidad. ${ }^{84}$

Si ya estaba adelantado en la cita anterior del De conscribendis epistolis la sinuosa, a la vez que delicada, argumentación por insinuación para aquello que se considera difícil de conseguir, ya sea por su propia naturaleza, ya sea por el interés propio en conseguirlo, Salinas sigue el mismo camino en su acopio del texto de Erasmo, recreando lo que precisa:

Primum exaggerantes, quanta nos circumstet necessitas, et quam magnum telum sit necessitas et quam inutilis pudor viro egenti; neque fugere nos quam sit improbum, rem tantam ab eo petere de quo nihil vnquam simus promeriti. Post haec paulatim per cuniculos ostendemus nobis non mediocrem spem porrigi ab insigni illius benignitate, qua solitus sit etiam ignotis et indignis opitulari, ob eximiam ingenii bonitatem, ad subleuandas omnium miserias propensi. Hic pudor non vulgariter commendat rogantem, quemadmodum improbitas alienat animum. Nullus enim libenter in eum confert beneficium, qui ceu debitum flagitat magisque poscit quam petit. ${ }^{85}$

Si es cosa no lícita y que puede dar pesadumbre no se deve pedir assí a la clara, mas poner primero en quánta necesidad estemos y quán rezia cosa sea la necessidad. Y aviendo tanta, no nos parescer que es bie $n$ tener mucho empacho de pedirlo, aunque sea a quien nunca hezimos servicio que lo meresciesse. Pero que nos basta para tomar atrevimiento de pedirlo a él más que a otro conoscer su mucha nobleza, con la qual suele favorescer a todos en qualesquier necessidades. Mostrando tener vergüença de importunarle, pero de manera que dé a entender tener gran confiança, porque mucho combida a negar quando se vee que el que pide está dudoso de alcançarlo. ${ }^{86}$

Como se puede comprobar, Salinas evita las cuidadosas reflexiones de Erasmo en lo que se refiere a la situación interna de la petición, de la cuidadosa contemplación del denso entramado exigido por la ausencia de aquel a quién se pide, previendo su estado de ánimo, la posible reacción y la situación subordinada a la que se encuentra abocado el que pide. El sentido práctico de la Rhetórica, la propia actitud mostrada por el autor, ofrece instrucciones precisas, mucho menos elaboradas y seguramente, por ello, menos ilustrativas y profundas.

Erasmo proseguirá con un análisis de las circunstancias argumentativas que pueden requerirse para cerrar este apartado y abrir el camino que le permita ampliar e ilustrar todas las posibilidades a través de ejemplos, dependiendo de la naturaleza fácil o difícil - proceder recto u oblicuo - de aquello que se solicite. Además, incluye un catálogo propio de posibilidades, al aire de las fórmulas proporcionadas para la composición y redacción de una carta.

Ya sea por su actitud decidida de no distinguir aquello que pertenece a la comunicación en presencia o en ausencia del receptor, o bien por evitar instrucciones

\footnotetext{
${ }^{84}$ Salinas, Rhetórica, 79.

85 Erasmo, "De conscribendis", 466, 2-12.

86 Salinas, Rhetórica, 79.
} 
precisas que corresponden claramente al arte epistolar, Salinas, por su parte, remitirá a lo ya tratado previamente en la Rhetórica, a propósito de la narratio, y cerrará el capítulo dedicado a la petición insistiendo en la clasificación genérica con un "aunque se pudiera poner mucho más", a la manera de un paréntesis de todo lo "mucho más" tratado por Erasmo:

Siempre considerando de aquel a quien pedimos si es conoscido, pariente o deudo. Si avemos rescebido otros beneficios dél, diziendo que desseamos deverle más, como quiera que no esperemos poder pagarle el menor beneficio. Y consideradas las otras circunstancias del tiempo y lugar como está dicho, lo demás buena discreción lo pondrá de suyo. Y con esto quiero acabar con el género deliberativo, aunque se pudiera poner mucho más. ${ }^{87}$

No será el único lugar tomado por Salinas del De conscribendis epistolis, si bien seguirá el mismo procedimiento ilustrado para la carta petitoria. Si las pautas mostradas por Erasmo para la petitoria epistola son muy claras y esquemáticas, distinto es el tratamiento «De consolatoria epistola», siendo mucho más amplio y en la misma medida será la adaptación que realiza Salinas. Sigue el mismo procedimiento que en el caso anterior, fijándose en todos aquellos puntos susceptibles de ser clasificados.

Así Erasmo plantea que «triplex erit ratio tractandae consolationis», dependiendo de la necesidad de consuelo del destinatario, bien porque dada su sabiduría no lo necesite, o bien porque el estado de sufrimiento sea de tal calibre que sea imposible hacerle entrar en razón, o, en tercer lugar, porque su propio orgullo le impida aceptar el sufrimiento. ${ }^{88}$ Salinas alterará el orden en dos sentidos, en primer lugar la ratio se reducirá a "dos maneras de consolación" 89 y reservará para el final la circunstancia que puede darse «Quando es el consolado de mucha más autoridad que el que le consuela» siguiendo en todo momento las pautas del De conscribendis epistolis. ${ }^{90}$ Para quien sufre en exceso, seguirá el razonamiento de Erasmo, con especial atención a la figura del médico que cura la herida abierta, incluso en la cuidadosa exposición que hace Erasmo sobre la pérdida del juicio y la necesidad de acomodarse a esa pérdida para desde ahí dar razones para el consuelo. Salinas procederá de la misma manera, desde la metáfora de la cura y la del médico que se afana en sanar el delirio. ${ }^{91}$

Frente a los anteriores, el género judicial merecerá un tratamiento breve, bajo el argumento común de que son las leyes en último término las que deciden, al hilo de la división dual peripatética establecida por Aristóteles al frente de su Retórica, y siguiendo en esto Salinas a Nebrija. Añadiendo, sin embargo, que «no dexa de servir quando se offresce contradezir alguna opinión o defenderla», lo que tratará ampliamente en términos ya argumentativos. ${ }^{92}$

\footnotetext{
87 Salinas, Rhetórica, 79.

${ }^{88}$ Erasmo, "De conscribendis", 432, 20-25 - 433, 5-10.

89 Salinas, Rhetórica, 76.

${ }^{90}$ Erasmo, "De conscribendis", 433, 5-10; Salinas, Rhetórica, 78.

${ }^{91}$ Erasmo, "De conscribendis”, 433, 15-30; Salinas, Rhetórica, 76.

92 Salinas, Rhetórica, 80.
} 
Una vez cerrado el apartado dedicado a la "división" aquel en el que ubica el tratamiento del De conscribendis epistolis de Erasmo, volverá Salinas a las partes comunes a todo discurso, es decir, a la confirmación, a la confutación y a la conclusión, lugar fundamental desde la perspectiva retórica y así considerada ampliamente en la Rhetórica por cuanto «los rhetóricos dividieron la conclusión en tres partes, en epílogo, amplificación y affectos» ${ }^{93}$ cerrando así el extenso tratamiento dedicado a la inventio para ocuparse de lo reservado a la siguiente de las partes artis, la dispositio, en su cualidad doble para alojar como parte estructural lo expuesto en la inventio y siempre desde el dictado de la causa y de las circunstancias, ${ }^{94} \mathrm{y}$ continuará con la inclusión más que interesante de lo que corresponde a las partes artis restantes: elocutio, memoria y pronuntiatio.

La influencia del De conscribendis epistolis de Erasmo no se quedará aquí y ocupará además un lugar vital para la ejercitación. La coherencia interna de la Rhetórica lo es también de una comprensión global en términos prácticos de aplicación, de tal convicción en su valía que incluso cabe la posibilidad de que sólo con el manual pudiera alcanzarse el dominio de la técnica, sin necesidad de «otro maestro». ${ }^{95}$ Así puede verse en el apéndice, no menos importante, en el que «Síguese una forma para poner por exercicio las reglas de la rhetórica pasada.» ${ }^{96}$

\footnotetext{
93 Salinas, Rhetórica, 96.

94 “Ay dos maneras de disposición, una según arte; otra según la especial qualidad de la causa y tiempo que se offresce. Según el arte ordenaremos si siguiéremos la orden que hasta aquí hemos traído de las partes de la oración, una después de otra, [...] La otra manera de disposición es que se queda al juizio del orador, según el tiempo y qualidad de la causa." Salinas, Rhetórica, 112. Para la doble dimensión que concede a la dispositio y en especial sobre el encaje de las partes orationis, Luis Alburquerque García, "La inventio en la Retórica de Miguel de Salinas", Actas del III Simposio Internacional de la Asociación Española de Semiótica, coords. José Romera Castillo y Alicia Yllera Fernández (Madrid: Universidad Nacional de Educación a Distancia, 1990), 119-126, 122.

${ }^{95}$ Así se introduce el apéndice: "Todas las cosas con exercicio son fáciles de alcançar y sin él non solamente diffíciles pero aun qualquiera diligencia que sea es perdida. Y por esto quiero poner aquí una forma como se exerciten las reglas de rhetórica passada presupuesto que hablo con quien no se ha de aprovechar de otro maestro, porque a tenerle por poco docto que fuesse le podría dezir mejor lo que para esto haze al caso." Salinas, Rhetórica, 150. Para el estudio de los tres apéndices que complementan el manual véanse las observaciones acerca de su sistematización clásica, a juicio de Iveta Nakládalová, en "la fórmula triádica capital" en la enseñanza de las artes: imitatio, ars y exercitatio. La lectura docta en la Primera Edad Moderna (1450-1650) (Madrid: Abada Editores, 2013), 138. Con respecto a los apéndices que complementan el tratado, son muy interesantes las apreciaciones realizadas por José Aragüés Aldaz en varios trabajos, subrayando la vertiente práctica del acomodo a la elaboración de un "cuaderno blanco" como apoyo para la composición del discurso. Resalta también Aragüés Aldaz la novedad y la autonomía del afán pedagógico de Salinas: "El apetito desordenado de saber': Erudición escolar y discurso renacentista en el Tratado de la forma que se debe tener en leer los autores de Miguel de Salinas", Revista de Filología Española, LXXX, 80, 3-4 (2000): 287-317; Aragüés Aldaz, José, "Miguel de Salinas o el arte de anotar" en Retórica aplicada a la literatura medieval y de los siglos XVI y XVII, ed. Lillian von der Walde Moheno (Ciudad de México: Ed. Destiempos, 2016), 13-38 y Aragüés Aldaz, José, “The 'white book' of Miguel de Salinas: Design, Matter and Destiny of a codex excerptorius" en Forgetting Machines: Knowledge Management Evolution in Early Modern Europe, ed. Alberto Cevolini (Leiden Boston: Brill, 2016), 209-223, https://data.isiscb.org/isis/citation/CBB650464707/ (consultado el 8 de enero de 2021).

${ }^{96}$ Salinas, Rhetórica, 150-158. Es preciso añadir que tanto por lo que se refiere al planteamiento teórico volcado en la comunicación y a la propuesta de ejercitación enfocada a la docencia, el intento de Salinas se aproxima al llevado casi al cabo de un siglo después por José de Ormaza en su Censura de
} 
Salinas ofrecerá varias posibilidades para «tomar un tema en que ejercitarse», todas ellas se convierten de por sí en tres propuestas prácticas sobre lo expuesto para cada uno de los tres géneros de la causa, por este orden, demostrativo, deliberativo y judicial, encauzándolo todo a propósito de lo tratado en la "división”:

Exemplo de lo primero sea esto: yo quiero, porque se me offresció al pensamiento por mi solo natural o por alguna cosa que se atravesó, escrevir la materia del monesterio de Guadalupe con todas sus particularidades, o alabar la vida y estado de la religión, o vituperar la guerra, o persuadir una hermana mía que críe con su propia leche un niño que parió. O a un amigo mío que se dé al estudio de las letras. O quiero deffender a uno que le acusan que mató a un hombre o acusarle. ${ }^{97}$

A continuación propondrá varias directrices que recorrerán lo explicado en el manual teórico y lo acompañará para su ilustración de un ejemplo tomado literalmente del De conscribendis epistolis, traído a propósito por Erasmo- a imagen de una epístola de San Jerónimo - ${ }^{98}$ para ilustrar, por su parte, «Quomodo proponenda materia», al comienzo mismo de su tratado y sin fijarlo desde los cauces de los géneros de la causa, por cuanto acoge también un modelo epistolar como el familiar. Salinas realiza un ajuste estructural a su medida y sitúa el ejemplo y su análisis al final del apéndice, absorbiéndolo en los tres géneros a efectos retóricos:

Esto está dicho generalmente y en breve; a averse de poner exemplos para todo y a la larga sería nunca acabar. Quiero poner sólo uno que ya Erasmo a este mismo effecto puso, aunque en unas partes pongo más que él y en otras menos. ${ }^{99}$

la elocuencia: Ma Amelia Fernández Rodríguez, "La Censura de la elocuencia (1648) de José de Ormaza: La idea retórica y poética del sermón”, en La corte del Barroco: Textos literarios, avisos, manuales de corte, etiqueta y oratoria, coords. Antonio Rey Hazas, Mariano de la Campa y Esther Jiménez Pablo (Madrid: Ediciones Polifemo, 2016), 543-576.

${ }^{97}$ La propuesta de desarrollar el tema sobre "persuadir una hermana mía que críe con su propia leche un niño que parió", está tomado desde el comienzo mismo del «Qvomodo proponenda materia», "Veluti si quis suadeat puerperae vt suo lacte alat quod peperit [...]" (Erasmo, "De conscribendis", 238, 21-22) sin relación alguna con lo expuesto por Erasmo y extraído, como ejemplo, con la intención de cuadrar la referencia a los tres géneros. Por otra parte, precede a la cita en el texto una observación tan interesante a efectos prácticos, propios también de la docencia, como la que sigue: "Lo primero que se deve hazer es tomar un thema en que exercitarse; y será por una destas maneras: O fingirálo según lo que querría tratar o alguna causa que se le aya offrescido o lo sacará de algún poeta o comedia o auctor que trate cosas fabulosas o de algú $n$ historiador verdadero". Salinas, Rhetórica, 68.

${ }^{98}$ Como señala en nota a pie de página Jean-Claude Margolin, se refiere Erasmo a la epístola 117 de San Jerónimo, Ad matrem et filiam in Gallia commorantes, Erasmo, "De conscribendis", 238.

99 Salinas, Rhetórica, 153. En nota señala Sánchez García: "«Lucius \& Antonius utrique adolescentes, sed alter mediocri fortuna, alter beatissimis parentibus natus, à primis annis sese non secus ac fratres amarant [...]» (De Conscribendis epistolis opus, Des. Erasmi Rot. Venetiis, Per Ioannem Patavinum, MDLI, p. 31). El ejemplo ilustra el apartado «Quomodo proponenda materia» y ocupa las pp. 31-33. Salinas analiza y descompone muy bien el texto erasmiano, eliminando solamente el detalle de la ciudad punto de partida de Lucio: Brujas." 
Con este ejemplo culmina Salinas todo el trabajo anterior, es sobre el que convergen la organización de un modelo profundamente coherente y original de la Retórica, no sólo por su comprensión, como por su reordenación a efectos no tanto de la oratio clásica como de lo requerido para situaciones concretas e interpersonales. A modo de conclusión, el intento de Salinas por escribir una Rhetórica en la propia lengua es ya de por sí una invitación a aplicarla a su momento histórico sin pensar siquiera que pueda ser instrumento para el acceso al estudio de los clásicos. Para ello moviliza todos los recursos desde una comprensión profunda de su sentido último y con la perspicacia absoluta de elegir para cada parte lo que le conviene para su proyecto. Si bien para sus coetáneos era más que conocido el De conscribendis epistolis de Erasmo y, por extensión, las artes epistolares, el acierto de Salinas consistió en integrarlo en el lugar preciso. Para ello contempló la posibilidad de incorporar lo debido al arte epistolar desde las circunstancias comunicativas y desde la tradición última de esta "retórica aplicada". 


\section{REFERENCIAS BIBLIOGRÁFICAS}

Albaladejo, Tomás, “Retórica y elocutio: Juan Luis Vives”, Edad de Oro, XIX (2000): 928.

Albaladejo, Tomás, "Cultural Rhetoric. Foundations and perspectives", Res Rhetorica, 1 (2016): 17-29. DOI: https://doi.org/10.17380/rr2016.1.2

Alburquerque García, Luis, "La inventio en la Retórica de Miguel de Salinas", Actas del III Simposio Internacional de la Asociación Española de Semiótica, coords. José Romera Castillo y Alicia Yllera Fernández (Madrid: Universidad Nacional de Educación a Distancia, 1990), 119-126.

Alburquerque García, Luis, "La vuelta a la Retórica y el Humanismo español (acerca de la inventio)", Actas del XI Congreso de la Asociación Internacional de Hispanistas. De historia, lingüisticas, retóricas y poéticas, coord. Juan Villegas (Madrid: Asociación Internacional de Hispanistas, 1994), I, 148-154.

Alburquerque García, Luis, El arte de hablar en público. Seis retóricas famosas del siglo XVI (Nebrija, Salinas, G. Matamoros, Suárez, Segura y Guzmán) (Madrid: Visor, 1995).

Aragüés Aldaz, José, “'El apetito desordenado de saber': Erudición escolar y discurso renacentista en el Tratado de la forma que se debe tener en leer los autores de Miguel de Salinas", Revista de Filología Española, 80, 3-4 (2000): 287-317.

Aragüés Aldaz, José, "Miguel de Salinas o el arte de anotar" en Retórica aplicada a la literatura medieval y de los siglos XVI y XVII, ed. Lillian von der Walde Moheno (Ciudad de México: Ed. Destiempos, 2016), 13-38.

Aragüés Aldaz, José, “The 'white book' of Miguel de Salinas: Design, Matter and Destiny of a codex excerptorius" en Forgetting Machines: Knowledge Management Evolution in Early Modern Europe, ed. Alberto Cevolini (Leiden Boston: Brill, 2016), 209-223, https://data.isiscb.org/isis/citation/CBB650464707/(consul tado el 8 de enero de 2021).

Arcos Pereira, Trinidad, "De Cicerón a Erasmo: La configuración de la epistolografía como género literario", Boletín Millares Carlo, 27 (2008): 347-400.

Asensio, Eugenio, "Los estudios sobre Erasmo de Marcel Bataillon", Revista de Occidente, 63 (1968): 302-319.

Artaza, Elena, El ars narrandi en el siglo XVI español. Teoría y práctica (Bilbao: Universidad de Deusto, 1989). 
Brocar, Joan de, "Epístola" en Salinas, Miguel de, Rhetórica en lengua castellana, ed. Encarnación Sánchez García (Nápoles: L’Orientale Editrice, 1999), 4-6.

Calero Calero, Francisco, Juan Luis Vives o Fray Miguel de Salinas. A propósito de la Rhetórica en lengua castellana (Madrid: Fundación Universitaria Española, 2008).

Casas, Elena, La retórica en España (Madrid: Editora Nacional, 1980).

Castillo Gómez, Antonio, “Vos, señor, la escribiste a la luna'. Aprendizaje, discurso y prácticas epistolares en la España Moderna”, Estudios Filológicos, 60 (2017): 3355.

Cicerón, Orator with an english translation by H. M. Hubbell, Cicero in twenty eight volumes, Cambridge (Mass. - London: Harvard University Press - William Heinemann Ltd., 1971), The Loeb Classical Library, 5.

Díez Coronado, María Ángeles, Retórica y representación. Historia y teoría de la Actio (Logroño: Instituto de Estudios Riojanos, 2004).

Erasmo de Rotterdam, "De conscribendis epistolis", ed. Jean-Claude Margolin, Opera omnia Desiderii Erasmi Roterodami. Recognita et adnotatione critica instructa notisque illustrata. Ordinis primi Tomvs secundvs (Amsterdam: Nort-Holland Publishing Company, 1971), 204-579.

Esteve Serrano, Abraham, "Contribución al estudio de las ideas ortográficas en España", Tonos. Revista electrónica de estudios filológicos, XIII (2007): https://www.um.es/tonosdigital/znum13/secciones/relecturas A ideas.htm (consultado el 8 de enero de 2021).

Fernández Rodríguez, M Amelia, Una idea de maravillosísima hermosura. Poética y Retórica ante la Lirica en el siglo XVI (Madrid: Ediciones de la Universidad Autónoma de Madrid, 2003), https:/ /libros.uam.es/?press $=$ uam\&page $=$ catalog\&op $=$ book \&path $\% 5 \mathrm{~B} \% 5 \mathrm{D}=76$ (consultado el 8 de enero de 2021).

Fernández Rodríguez, Ma Amelia, "La Censura de la elocuencia (1648) de José de Ormaza: La idea retórica y poética del sermón", en La corte del Barroco: Textos literarios, avisos, manuales de corte, etiqueta y oratoria, coords. Antonio Rey Hazas, Mariano de la Campa y Esther Jiménez Pablo (Madrid: Ediciones Polifemo, 2016), 543576.

Fumaroli, Marc, “Genèse de l'épistolographie classique: Rhétorique Humaniste de la Lettre, de Pétrarque à Juste Lipse [with Discussion]." Revue D'Histoire Littéraire De La France, 78, 6 (1978): 886-905. 
Gómez Alonso, Juan Carlos, "Retórica y Poética en los siglos XVI y XVII: La operación retórica de memoria", Edad de Oro, XIX (2000): 121-130.

Gonzalo Sánchez-Molero, José Luis, La "librería rica” de Felipe II. Estudio histórico y catalogación (San Lorenzo del Escorial: R.C.U. "Escorial-Ma Cristina", Servicio de Publicaciones, 1998).

Gonzalo Sánchez-Molero, José Luis, Felipe II. La educación de un "felicísimo príncipe" (15271545) (Madrid: Consejo Superior de Investigaciones Científicas - Ediciones Polifemo, 2013).

Gonzalo Sánchez-Molero, José Luis, "Fray Juan de Valladolid (OSH): lector del Novum instrumentum de Erasmo y autor de la Rhetórica en lengua castellana (1541)" en Grandes y pequeños de la literatura medieval y renacentista, coord. Emilio Blanco (Salamanca: Universidad de Salamanca, Sociedad de Estudios Medievales y Renacentistas (SEMYR), 2016), 307-331.

Guillén, Claudio, "Para el estudio de la carta en el Renacimiento" en La epistola, ed. Begoña López Bueno (Universidad de Sevilla: 2000), 101-127.

Henderson, Judith Rice, "Defining the Genre of the Letter Juan Luis Vives 'De Conscribendis Epistolis", Renaissance and Reformation / Renaissance et Réforme, 7, 2 (1983): 89-105.

Henderson, Judith Rice, “The enigma of Erasmus' Conficiendarum epistolarum formula", Renaissance and Reformation / Renaissance et Réforme, 25, 3 (1989): 313330.

Henderson, Judith Rice, "Erasmian Ciceronians: Reformation Teachers of LetterWriting", Rhetorica. A Journal of the History of Rhetoric, 10, 3 (1992): 273-302.

López Grigera, María Luisa, La retórica en la España del siglo de oro. Teoría y práctica (Salamanca: Ediciones de la Universidad de Salamanca, 1994).

Margolin, Jean-Claude, "Introduction" a su ed. Opera omnia Desiderii Erasmi Roterodami. Recognita et adnotatione critica instrvcta notisqve illustrata. Ordinis primi Tomvs secundvs (Amsterdam: Nort-Holland Publishing Company, 1971): 157-204.

Martí, Antonio, La preceptiva retórica española en el Siglo de Oro (Madrid: Gredos, 1972).

Martín Baños, Pedro, El arte epistolar en el Renacimiento europeo. 1400-1600 (Bilbao: Servicio de publicaciones de la Universidad de Deusto, 2005). 
Martín Baños, Pedro, "Familiar, retórica, cortesana: disfraces de la carta en los tratados epistolares renacentistas", Cuadernos de Historia Moderna. Anejos, 4 (2005): 15-30.

Martín Jiménez, Alfonso, Retórica y Literatura en el siglo XVI. El Brocense (Valladolid: Universidad de Valladolid, 1997).

Monfasani, John, “Three Notes on Renaissance Rhetoric”, Rhetorica, 5, 1 (1987): 107 118.

Moriyon Mojica, Carlos, "Valdés y Salinas. Dos actitudes frente a la lengua", Estudios de Lingüistica. Universidad de Alicante, 5 (1988-1989): 291-301.

Murphy, James J., La Retórica en la Edad Media. Historia de la teoría de la retórica desde San Agustín hasta el Renacimiento, trad. G. Hirata Vaquera (México D. F.: Fondo de Cultura Económica, 1986).

Nakládalová, Iveta, La lectura docta en la Primera Edad Moderna (1450-1650) (Madrid: Abada Editores, 2013).

Poch Olivé, Dolors, "La buena y docta pronunciación según Miguel de Salinas”, eds. Emilio Montero Cartelle y Carmen Manzano Rovira, Actas del VIII Congreso Internacional de Historia de la Lengua Española (Santiago de Compostela: Meubook-Asociación de Historia de la Lengua Española, 2012), II, 1753-1764.

Quintiliano: The Institutio Oratoria of Quintilian in four volumes, ed. Harold Edgeworth Butler (Cambridge Mass. - London: Harvard University Press - William Heinemann Ltd., 1966), The Loeb Classical Library.

Rivas Hernández, Ascensión, "Miguel de Salinas, la retórica y la Modernidad”, eds. Antonio López Eire, Juan Miguel Labiano Ilundain y Antonio M. Seoane Pardo, Retórica, política e ideología. Desde la Antigüedad hasta nuestros días. Actas del II Congreso Internacional (Salamanca: LOGO: Asociación Española de Estudios sobre Lengua, Pensamiento y Cultura Clásica, 1998), II, 47-52.

Rico Verdú, J., La retórica española de los siglos XVI y XVII (Madrid: CSIC, 1973).

Russell, Peter E., "Un libro indebidamente olvidado. La Rhetórica en lengua castellana (1541) de Fray Miguel de Salinas", en Libro-homenaje a Antonio Pérez. Gómez, ed. Joaquín Pérez Gómez (Cieza: ... la fonte que mana e corre..., 1978), II, 133-142.

Salinas, Miguel de, Rhetórica en lengua castellana, ed. Encarnación Sánchez García (Nápoles: L’Orientale Editrice, 1999). 
Salinas, Miguel de, Tractado para saber bien leer y escrevir, pronunciar, cantar letras assí en latín como en romance (Zaragoza: Pedro Bernuz, 1551).

Salinas, Miguel de, Libro apologetico que defiende la buena y docta pronu[n]ciacio[n] q[ue] guardaro[n] los antiguos en muchos vocablos y accentos, con las razones que tunieron y ay para se tener, que fue buena y sabia y no ignorante ni mala segu[n] que algunos delos modernos ha $[n]$ reprehendido y condenado (Alcalá de Henares: Casa de Pedro Robles y Fra[n]cisco de Cormellas, 1563).

Sánchez García, Encarnación, “'Alta sciencia y provechosa': la Rhetórica en lengua castellana (Alcalá, 1541) de Miguel de Salinas", en Actas del XII Congreso de la Asociación Internacional de Hispanistas. Estudios áureos II, ed. Jules Whicker (Birmingham: University of Birmingham. Department of Hispanic Studies: 1998), III, 221-228.

Sánchez García, Encarnación “Introducción” a su ed. Salinas, Miguel de, Rhetórica en lengua castellana, (Nápoles: L’Orientale Editrice, 1999), v-xliii.

Sánchez García, Encarnación, "Nebrija y Erasmo en la Rhetórica en lengua castellana de Miguel de Salinas", Edad de Oro, XIX (2000): 287-298.

Sigüenza, José de, Historia de la orden de San Jerónimo (Madrid: Bailly Baillière e Hijos, 1907-1909), 2 vols.

Trueba Lawand, Jamile, El arte epistolar en el Renacimiento español (Madrid: Támesis 1996).

Vicente Gómez, Francisco, "La tensión inventio-elocutio en la Rhetórica en lengua castellana de Miguel de Salinas", en Los Humanistas españoles y el Humanismo europeo. Actas del IV Simposio de Filología Clásica (Murcia: Servicio de publicaciones de la Universidad de Murcia, 1990), 255-260.

Vives, Juan Luis, "Redacción epistolar (De conscribendis epistolis)" en Obras completas, ed. Lorenzo Riber (Madrid: Aguilar, 1947-1948), I, pp. 841-879.

Recibido: 1 de marzo de 2021

Aprobado: 6 de abril de 2021 